It is possible to cure this discharge by injection by this method into the cervical glands.

Cervical infection is always possible in gonorrhea in the female, but by prompt action, tubes, etc., may be spared future disease.

So far lactic acid used by this method is the best drug for injection.

A too deep injection of the lactic acid may cause a slough, which, while not dangerous, is to say the least annoying, and lessens the good result which should be obtained from said injection.

2010 Chestnut St.

\section{A CASE OF CEPHALIC TETANUS, WITH PARALYSIS OF BOTH SEVENTH NERVES.}

JAMES HENDRIE LLOYD, A.M., M.D.

Neurologist to the Philadelphia Hospital PHILADELPHIA.

In $18 \% 0$, Rose ${ }^{1}$ described a rare form of tetanus in which the tetanic symptoms were sometimes (but not always) confined to the muscles of the jaw and throat and were associated with a paralysis of the seventh nerve. This paralysis of the seventh nerve may be said to be the most distinguishing symptom of this form of lockjaw, and the cases thus far reported have, without exception, arisen from wounds in the territory of the fifth nerve.

Although paralysis of the seventh nerve is the most characteristic symptom, this nerve is not the only one paralyzed in all cases, for in very few instances the motor nerves of the eye, the hypoglossal nerve, and the branches of the pneumogastric nerve supplying the muscles of the pharynx, have also been involved. Such an anomaly as these local palsies present in cases of lockjaw could not fail in time to attract attention, and the disease has been variously named cephalic tetanus, kopftetanus, and tetanus hydrophobicus, the last name having been used by Rose because of a fancied, but quite superficial, resemblance to rabies.

It was not until $\mathbf{1 8 8 \%}$, however, that the disease was first described in France by Terrillon, ${ }^{2}$ and in America it seems even yet to be rare, for comparatively few reports of cases are on record. The best American paper is by Willard, ${ }^{3}$ of Philadelphia, who, in 1895, published the report of a case in a boy and collected references in the whole literature to seventy-four cases, his own heing the seventy-fifth. There are few other cases which have appeared since Willard published his paper or which escaped his observation.

In the vast majority of all reported cases the paralysis of the facial nerve has been unilateral, and this paralysis has been almost, if not quite, always on the side of the wound. A very few cases, however, of double facial palsy have been noted-so few, indeed, that I have found but six, possibly seven, examples. In these few cases, the wound, with but one exception, had been in the median line, usually on the nose, or on the bridge of the nose, or on the forehead. The case which is reported in the present paper is an instance of this

1. Handbuch der Chir., von Pitha and Billroth, vol. 1, Ab. 11, No. 11, p. 5 .

2. Rev. de Chir., 1888, No. 1.

3. 'Teans. Col, of Phys. of Phila., 1895, p. 27. Willard refers to a previous case reported by Hunt (T'rans Col. Phys., Phila. 1862, May 7, vol. 111, N. S. p. 466), but Hunt's case was not one 1862 , May 7 , vol. 11.1 , N. S. p. 466), but Hunt's case was not on
of cephailic tetanus. It was i case of punctured wound of the cranium, with injury to the brain, causing hemiplegia. The patient died of general tetanus, not kopftetanus with facial palsy. double facial palsy, or facial diplegia, occurring in cephalic tetanus; and, as it is possibly only the seventh, or at most eighth, aase of the kind to be observed with care, it has been deemed worthy of a special report.

Patient.-Mrs. K. O., aged 41, white.

History.-The patient first came to the Methodist Episcopal Hospital on Sunday, May 28, giving a history of having fallen downstairs eighteen days previously and having sustained an open wound on the bridge of the nose. The nose was swollen for a day or so, and the wound was covered with a small piece of court plaster. The patient felt no disability from the injury, except the discomfort from the wound, until fourteen days later, when she noticed her face beginning to draw toward the right side. She gradually became unable to move her lips, or to separate her jaws, and dysphagia soon developed.

Examination.-On examination by the resident physician, the following conditions were noted: The face was smooth and "ironed out;" the patient was unable to close her eyes, to wrinkle her forehead, to move her lips, to open her jaws or to swallow without diffieulty. If the lips were held open by

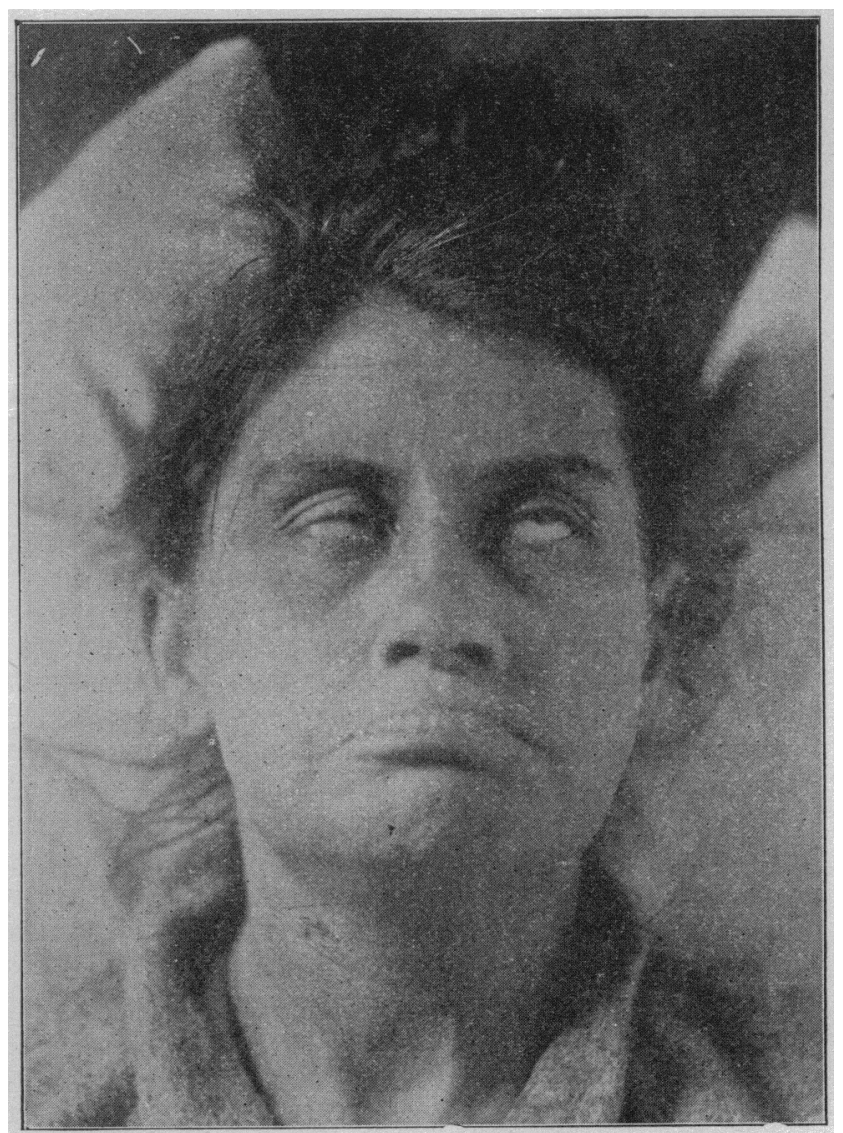

This shows the patient in the atrempt to close the eyes. It also shows the trismus and the slight wound on the median line of the nose from which the infection occurred. The smooth expressionless appearance of the face and brow is also shown.

her fingers, she could articulate imperfectly; otherwise she answered in grunts. Sensation over the distribution of the fifth nerve was normal. The patient returned on the following Tuesday, when Dr. Holmes, under nitrous-oxid gas, found a spasm of the muscles of mastication, but no surgical condition present. The patient's friends said that she was able to close her eyes, to open her mouth, and to swallow until two weeks after the injury.

When the patient was examined by Dr. Lloyd, on June 2, the conditions were noted as follows:

The head is freely movable in all directions; no retraction of the head; no paralysis in any limb. A wound on the bridge of the nose is covered with a scab. The patient does not talk clearly, but answer's mainly in grunts. She claims 
that she is able to swallow, but complains of the accumulation of saliva and phlegm in the throat. She swallows water at request when it is given slowly through a space left by an extracted tooth, the patient lying on her back during the process. The larynx does not seem to rise as fully as in the normal act of swallowing.

Third, Fourth and Sixth Nerves: There is no involvement of any one of these nerves. Both the exterior and interior muscles of the eye act normally. The balls move freely in all directions. The pupils react normally to light and on accommodation and convergence.

Fifth Nerves: There is no anesthesia in the distribution of the fifth nerves. In the effort of chewing there is very slight movement of the masseters and temporals, but not enough to move the jaw, which is firmly set; and these muscles are felt to be rigidly contracted.

Seventh Nerves: There is slight ability to raise the right corner of the mouth. There is no sardonic grin, no tetanic rigidity of the facial muscles. In the act of trying to close the eyes, the balls roll far upward, but the orbicular muscles do not move, and the lids do not cover the whites of the eves. There is no wrinkling of the brow. When laughing, there is no expression of the features indicating that act. The patient is unable to whistle, to puff out the cheeks, or to show the teeth. All the muscles of both sides of the face are paralyzed, except for the slight movement in the right corner of the mouth. The paralysis of both facial nerves is thus seen to be classical. The upper and lower fibers are alike involved. Both orbicular muscles are paralyzed; the patient can not close her eyes, and when she attempts to do so the eyeballs roll far upward until the cornex are concealed beneath the upper lids. The brow and face are smooth and motionless, and the lips are powerless. The mask-like, expressionless appearance of the face is striking.

Twelfth Nerves: The patient claims that she can move her tongue; but this act can not be seen, because of the spasm of the jaw.

The trismus is extreme. The jaws are firmly set, and the patient can not separate the teeth to the slightest extent. In making an effort to talk she uses her fingers to separate the lips, which are flaceid and powerless. There is no tetanic involvement of the muscles of the neck, trunk. or limbs. No retraction of the head nor opisthotonus is present, or has been present.

The patient has no paralysis of the extremities. She is able to use her hands and arms perfectly, and walks with a natural gait; in fact, she walked into the hospital. The general condition is good; pulse and temperature are normal.

Course of the Disease.-The patient declined to remain in the hospital, and returned to her home, where she was treated by her family physician, Dr. William Irwin, to whose kindness I am indebted for the opportunity of continuing to see the case until the end.

June 7 , the patient is slightly better. The eyes shut a little better, otherwise the symptoms are about the same. When she tries to talk, which she does very imperfectly, she holds the paralyzed lips apart with her fingers in order to enunciate more clearly (a characteristic action which has been noted in several of the reported cases). She is much annoyed by the accumulation of saliva, which tends to escape from between the paralyzed lips. The trismus is still complete; the lower jaw is clamped rigidly to the upper and is motionless. The patient is fed with fluids through a space left by an extracted tooth. There is to-day no true dysphagia or suffocation on swallowing, although from the statement of her attendants there has been something of the kind at times. There is no extension of the tetanic spasms to the neck, trunk or limbs. There is no paralysis of the limbs; the knee jerks are slightly increased, also the biceps jerks. There is no Babinski, or Oppenheim, or MeCarthy reflex. The attempt to laugh produces a curious result; there is an odd sound, as of a chuckle, in the throat, but the face remains motionless. The general condition is fairly good; pulse 100 ; temperature normal.

June 16, examination with Dr. Irwin. The patient is better. She has regained some power in the face, more on the right side, and is able to draw the corner of the mouth farther over to that side. She is still unable to shut her eyes, to wrinkle her brow, to whistle, or to laugh. There is some reIaxation of the jaw, as is seen on attempts at chewing, and as is proved by the fact that the patient has bitten her tongue. This also proves that she is able to move her tongue. The lower jaw, nevertheless, is still very rigid. There are no ocular palsies, or fifth nerve palsies, sensory or motor. There is no spasm on deglutition, nor of the neck or trunk. Saliva still tends to dribble from between the lips. General condition is good. The treatment by Dr. Irwin has been with chloral and the bromids. No antitetanus serum has been used at any time in the case. The prognosis seems very favorable to-day.

July 3, the patient has improved greatly, and has been out to walk. She ean shut her eyes, wrinkle her forehead and whistle, but the lower fibers of the seventh nerves are still somewhat involved, more than the upper. The jaw is much relaxed, but still a little stiff. The eye muscles are normal. The expression of the face on laughing is still peculiar. The patient can be pronounced convalescent.

From this time the progress of the case was steadily onward to recovery. The whole duration of the tetanus was about six weeks.

\section{CHIEF FACTS OF NOTE IN CEPHALIC TETANUS.}

The following are some of the main facts to be noted in cases of cephalic tetanus:

The Seat of the Wound.-In the majority of cases of cephalic tetanus, the facial paralysis has been onesided, and the wound, too, has been on one side, the paralysis being on the same side as the wound. Exceptions to this rule have been rare, and even open to doubt. A wound on the right side of the face does not cause facial paralysis on the left side, or vice versa. In all the cases of facial diplegia, howerer, except that of Roberts', the wound has been in the median line of the face, nose or forehead, but not every wound in the median line has produced bilateral symptoms, as witness the cases of Nankevell. ${ }^{4}$ and Oliva, ${ }^{5}$ in which the wound was on the bridge of the nose, but the facial paralysis was on the right side of the face only; the case of Wagner, ${ }^{B}$ in which the wound was in the center of the forehead, and that of Nerlech, ${ }^{7}$ in which the wound was at the root of the nose; but in both cases the paralysis was in the distribution of the left facial nerve. By far the greater number of observers place the paralysis on the same side as the injury. On whichcrer side it occurs, however, the wound in cephalic tetanus is in the area of distribution of the fifth nerve, the commonest point being in what some authors call the orbital-nasal-temporal angle. One case has been reported, that of Pollock, in which the wound was in the eyeball, and another in which it was in the mouth. In the few cases in which the muscles of the eve have been paralyzed, the wound has been on or near the lid, but not all cases of wound on or near the lid have caused ocular paralyses.

The Character of the Paralysis. The paralysis of the seventh nerve has all the characteristics of a peripheral paralvsis; hence, it is like a genuine Bell's palsy. Both the upper and lower fibers are involved. The brow, the orbicularis palpebrarum, the small muscles of the face and lips, all are involved. Consequently, the patient can not wrinkle the brow, close the eve, move the face or lips, whistle, or display the teeth; and in unilateral cases the characteristic deformity is present, as caused by the flattening of the nasal fold and the drawing of the face toward the sound side. For some unknown reason, howerer, the reactions of degencration are not present.

\footnotetext{
Gaz de Chir., 1886.

6. Schmidt's Jahrbuch, 1884, p. 189

7. Inaug. Dissert., Halle, 1 si2.
} 
The Tetanic Symptoms.-Trismus is always a marked symptom, and in some cases it is the chief or even the only tetanic symptom. In not a few cases nowever, the tetanus extends to other muscles, as of the throat, neck, trunk, and limbs, the case thus presenting the picture of a more or less general tetanus. As a rule, however, the symptoms of cephalic tetanus are not so widespread or severe as in the ordinary type-a fact which bears on the prognosis.

Paralysis of Other than the Facial Muscles.-In a very few reported cases, the muscles of the eyes have lren paralyzed. Thus, in Roberts' case, the left eyeball was completely immobile, while in the right orbit only the third and fourth nerves were paralyzed, the sixth escaping. The wound was under the left eye. In one case, ${ }^{8}$ ptosis was observed. Willard makes no reference to these complications, so they are probably rare. v. Schrötter ${ }^{0}$ reports a case of hopftetanus in which there was paralysis of the facial, the ocular, and the hypoglossal nerves. Neumann ${ }^{10}$ claims that the facial nerve is paralyzed first: then the oculomotor, abducens, trochlear and hypoglossal are affected in the order named; but the number of reported cases is too small to admit of such a dogmatic rule. In most cases, the paralysis of the facial nerve has appeared at about the same time as the lockjaw.

\section{PROGNOSIS.}

Cephalic tetanus is not quite so severe a disease as the ordinary type of tetanus. More patients recover than in the usual form of Iockjaw. Nevertheless, it is a very grave affection, with a high death rate, as the reported cases prove. From Willard's table we learn that of 45 "acute" cases (counting those as acute in which the lockjaw supervened within the first week after the wound) 39 patients died and only 4 recovered, a mortality of 90 per cent. Of 32 "chronic" cases (after the first week), 8 patients died and 24 recovered, a mortality of 25 per cent. This difference is striking and shows very conclusively that the important factor in prognosis is the date of onset of the tetanus after the reception of the wound. Gowers has claimed that the age of the patient is the determining factor; that all cases in patients over 25 years of age are fatal; but Willard's table disproves this claim effectually, for 15 of the patients who recovered were over 25 years of age. In the case reported in this paper, the patient was 41 years old and made a good recovery, but she comes within the "chronic" group, for the lockjaw did not appear until the fourteenth day. Willard's table also proves that in the "local" cases, i. e., those in which the tetanic symptoms are confined to the jaw, throat and neck, the prognosis is better, for 14 patients recovered and 15 died; while of the "general" cases, in which the tetanus is widespread, 14 patients recovered and 32 died. This is in accord with what might be expected. In the present case, the tetanus was strictly limited to the jaw, and the patient recovered, her condition never presenting such a grave appearance as is seen in generalized tetanus. On the other hand, the majority of the cases of facial diplegia have been fatal; in the $y$ cases noted, only 2 patients recovered, one of them being $m y$ case; but these fatal cases also have all been in the "acute" group.

REVIEW OF THE CASES IN THE LITERATURE.

The following are brief statements of the cases of

8. I'Unton Med., 1886, No. 173 .

9. Wein klin. Wochet, 1902 , Yo 2, p. 56 .

10. Zeit. f. Heilkunde, 1902 , p. 344 . facial diplegia in cephalic tetanus that havo been collected:

Thenée's Case. ${ }^{11}$-The wound was on the root of the nose, hence probably in the median line. It is reported as a case of "one-sided trismus," but there was also paralysis of the left side of the face, followed by paralysis of the right side. It proved fatal on the ninth day after the wound.

Roberts' Case. ${ }^{12}$-'The wound was under the left eye, with early onset of tetanus and general convulsions. The left facial nerve was paralyzed completely, also the upper distribution of the right facial nerve. 'The left eye was complctely immobile, while on the right sile the third and fourth nerves were paralyzed, the sixth escaping. The case was fatal.

Huntingdon's Gase. ${ }^{13}$--The wound was a little above the root of the nose-hence, probably in the median line. There was complete bilateral facial paralysis, but no orbital paralyses. Dysphagia was present, with profuse salivation. Trismus and cramps in the legs and trunk muscles occurred. Recovery took place in six weeks.

Bourgeois' Case. ${ }^{14}$-This patient was a gardener. The wound was in the median line on the nose. Both seventh nerves were totally paralyzed. Convulsions were general; the patient had dysphagia and spoke with difficulty, using his fingers to open his lips. The onset of the tetanus was on the sixth day, and death occurred on the third day after the first appearance of the lockjaw.

Crouzon's Case. ${ }^{15}$-The wound was in the median line at the root of the nose, and both seventh nerves were paralyzed. The patient used his fingers to separate the paralyzed lips in speaking. The case terminated fatally on the thirteenth day from the reception of the wound, the convulsions having become general.

Bouchaud's Case. ${ }^{10}$-The patient was a gardener. The wound was on the nose in the median line. The patient could not swallow liquids and spoke with great difficulty. Both seventh nerves were totally paralyzed, the paralysis being of the peripheral type. There was possibly some weakening also of both superior recti muscles of the eyes. Slight power remained in the lips. (Does this indicate that the lips are partially innervated by the twelfth nerves?) The patient, as in other cases, used his fingers to separate the lips in attempting to speak. Attempts at swallowing brought on suffocation. There were no tetanic spasms in the neck, trunk or limbs. An interesting feature was the fact that the patient was an epileptic, and had one epileptic seizure during his illness; but unfortunately it was not noted whether the paralyzed facial muscles were convulsed during this fit. The tetanus appeared on the sixth day after the wound, and death occurred six days later.

Carettis Case-Bouchaud refers to a case of facial diplegia in cephalic tetanus, reported by Caretti, but I have not secured the report of this case.

\section{COMMENTS.}

There has been much speculation about the nature of the paralysis of the facial nerve in cephalic tetanus. It is a uniqus phenomenon, for tetanus does not cause paralysis in other parts of the body. As these cases

11. Berl. klin. Woeh., 1880, p. 531.

12. Iancet, July 11, 1891.

13. I ancet, Sept. 1i, 1892

14. Gaz. đe Hôp., 1900 , p. 418.

15. Rev. Neurol.

16. Jollr, de Neurol., $1905, \mathrm{~lx}$, p. 40 
all occur from wounds in the area of distribution of the fifth nerve, the hypothesis of a reflex paralysis has been invoked, but it explains nothing. Tetanus is an infectious discase, caused by a microbe. This microbe gains entrance in these cases at a point where it can exert a direct action on the seventh nerres, and its effect is to paralyze one set of nerve fibers (the seventh) while it causes tetanic spasm in neighboring nerves (the motor branches of the fifth). It might well be called tetanus waradoxus. Some observers have claimed that the trismus also has a tendency to be unilateral, or at least more marked on the side of the wound.

Vaillard (quoted by Bourgeois) denied that the facial nerve is truly paralyzed in these cases; he seemed to think that it was in tetanic spasm. It has been sugcested that the asymmetry of the face is not due to paralysis, but to excessive tetanic spasm in the muscles of the opposite side. ${ }^{17}$ Such an explanation, however, falls completely to the ground in those cases in which both facial nerves are paralyzed. Moreover, it can not explain the typical inability to close the eye and to wrinkle the brow and all the other classical symptoms of Bcll's palsy. It has also been suggested (by Bernharlt and by Guterbrock) that the paralyzed muscles are also contractured; but this does not appear to be so on close examination. The passive raising of the lips by the breath on expiration, and the lifting of the flaccir lips by the fingers in attempts at speaking (a characteristic act) are clearly indicative of paralysis.

Some of the clinical observations here recorded have been confirmed by experimental work, especially with reference to the seat of the wound. Brunner ${ }^{18}$ injected the tetanus toxin into guinea-pigs and obtained symptoms on the same side into which the toxin was injecter; and if it was injected into the median line, the symptoms were bilateral.

The pathology of this facial paralysis in cephalic tetanus has not been satisfactorily determined, although a number of autopsies have been made. Tho results, however, are negative. The reactions of degeneration have not been obtained. This was so in Willard's case, in which I made the tests. In the case reported in this paper the opportunity to make an electrical sturly was not farorable.

There has been no attempt in this paper to go into an exhaustive review of the literature. Willard's paper, already quoted, gives a long list of reforences and it is easily accessible. The attempt has been made here. however, to collect all the cases in which the facial paralysis was bilateral. Willard, in a review of 75 cases of cephalic tetanus. found but 2 in which both serenth nerves were involved. With the assistance of Dr. C. D. Camp, I have studied about 25 additional cases of lopftetonus remorted in the last ten rears, or not included in Willard's list, and have found a total of 7 cases of facial diplegia, as abstracted above, the present case being the eighth.

Important papers on the subject of cephalic tetanus are by Villar, ${ }^{19}$ Bernhardt, ${ }^{20}$ Dard, ${ }^{21}$ and Sapincourt, ${ }^{22}$ the last two of which have not been accessible to me.

17. Trosselin : Gaz. d. Hôp., 1880. 1x, p. 65.

18. Deut. Zeit. f. Chir., $x \times x$, p. 574 ; also Beitrïg f. klin. Chir., ral. 9, p. 269.

19 Gaz. de Hôp., 18.88 , p. 1357

20. Zeit. f. klin. Med., 1884 , p. 410 .

21. 'Thesis, 1896.

22. Iiev. Med. de Normand, 1904, iv, 333.

\section{ATANIA OF CENTRAL ORIGIN APPEARING IN CHILDHOOD.*}

ARTHUR WILLARD FAIRBANISS, M.D. BOSTON.

This paper is a brief consideration of a form of central nervous disease previously described under the titles of hereditary ataxia, cerebellar ataxia, and not infrequently under the heading of Friedreich's disease: It varies, in certain particulars, howerer, as we shall see, from the usual conception of what should constitute the affection bearing Friedreich's name. In view of its relative rarity, the number of cases of this affection coming under the observation of any single observer is naturally small.

The clinical characteristics of this affection stated briefly are: Muscular inco-ordination commencing usually in childhood, and, as a rule, first affecting the muscles of the lower extremities, thence extending to the upper extremities, and to the muscles of the trunk, head, larynx, tongue and eyes; slowness of muscular response to rolitional impulse; swaying, unsteady gait; slow, hesitating or deliberate speech, sometimes of nasal character and occasionally explosive; nystagmus; oscillation or tremor of head, body or extremities; and certain involuntary movements, which may or may not be of choreiform character, and which may occur independently or may be associated with rolitional intended movement of some other part of the body; lateral currature of the spine; deficient energy in carrying out voluntary movements; and, in an advanced period of the disease, paralysis, muscular spasm and contractures.

To this symptom-complex may be added, during the course of certain cases, various other symptoms not sufficiently invariable to be considered characteristic, but nevertheless to be regarded as inherent, although less common, phenomena. Among these may be mentioned vertigo, headache, optic atrophy and impairment of pupillary action and of the movements of the ocular muscles, apathy of facial expression, a tendencr to involuntary and improvoked laughter, loss of miscular tone, sensory disturbance, peculiar deformity of the feet, trophic changes in muscles, and very rarely interference in the action of the sphincters and trophic changes in the skin.

Certain other phenomena must be regarded in the light of complications, since they are clearly due to inrolrement of those parts of the central nervous structure, primary affection of which would produce a clinical picture totally different from the one we are considering.

Such is the occurrence of psychical phenomena, depreciation of intellectual nower, or cpileptiform attacks. In this srmptom-complex will be recognized many of the symptoms that characterized the well-known cases described by Friedreich in 1861, and which have since been identified with his name. Since then many cases have been reported differing so widely from the type originally described that certain observers have been led to believe that the were dealing with an affection of different nature. Several of these cases were undoubtedly not instances of Fricdreich's discase, and even in the light of our present knowledge of how manifold mav be its symptom-complex, bore in their clinical characteristics no resemblance whatever to the affection. The

* Read in the Section on Diseases of Children of the American redical Association, at the Fifiy-sixth Annual Session, July, 1905. 